\title{
Controller Design For DFIG Driven By Variable Speed Wind Turbine Using Static Output Feedback Technique
}

\author{
Om Prakash Bharti \\ Department of Electrical Engineering \\ Indian Institute of Technology \\ Banaras Hindu University \\ Varanasi-221005, Uttar Pradesh \\ India \\ opiitbhu@gmail.com
}

\author{
R. K. Saket \\ Department of Electrical Engineering \\ Indian Institute of Technology \\ Banaras Hindu University \\ Varanasi-221005, Uttar Pradesh \\ India \\ rksaket.eee@iitbhu.ac.in
}

\author{
S. K. Nagar \\ Department of Electrical Engineering \\ Indian Institute of Technology \\ Banaras Hindu University \\ Varanasi-221005, Uttar Pradesh \\ India \\ sknagar.eee@iitbhu.ac.in
}

\begin{abstract}
This paper describes the controller design for a DFIG based wind energy generation system using the static output feedback technique through the LMI Toolbox. The features of the DFIG, its converters and their controllers are discussed. The lower order nominal representation of DFIG is obtained using numerical differentiation of the SIMULINK model which is subsequently used for PID controller design. The obtained results are compared with existing methods for performance enhancement of the DFIG and wind energy conversion systems.
\end{abstract}

Keywords-DFIG; Wind turbine; MATLAB SIMULINK models; PID controller; linear matrix inequalities; SOF technique

Abbreviations: DFIG: Doubly Fed Induction Generator, PI: Proportional Integral, SOF: Static Output Feedback, LMI: Linear Matrix Inequality, FACT: Flexible AC Transmission, PFC: Power Factor Control, VSC: Voltage Source Converter, WEC: Wind Energy Conversion, PCC: Point of Common Coupling

\section{INTRODUCTION}

The investigation of progressively alternate energy sources, demand for electric energy is increasing very fast. Among the obtainable alternate energy sources, wind energy, solar energy and fuel cells have drawn considerable attention. Additional, all of these alternate energy sources are also of renewable nature. Among the mentioned alternate energy sources, wind power generation systems have been the most cost competitive alternative. Since the direction and speed of winds may vary from location to location as well as from time to time, the variable speed wind turbine technology offers inherent advantages over the fixed speed one [1]. The doubly fed induction generator (DFIG) is used in cycle with the wind turbine to produce electric energy. The DFIG through the use of the two back to back converters, rotor side and grid side converters, is able to deal with a wide variation of wind speeds by injecting a compensating variable frequency current component in the rotor circuit. This facilitates both super and sub synchronous operations of DFIG. It is well known that the induction machine is widely used in industrial application due to its low cost, simplicity of construction and low maintenance cost. Such type of machines can be used for electric generation where the speed of the prime mover is constant i.e. just above the synchronous speed. However, it is a fact that the wind speed varies drastically depending upon the environmental conditions and time of operation. Thus, there is a large margin of speed variation. Such large margins of speed variation makes wound rotor induction machines suitable for generation of wind energy [2]. In addition to its large speed variation, the wound rotor induction machine offers additional advantage of bidirectional transfer of the rotor power which depends on the rotor speed and field speed [3]. The DFIG is essentially a wound rotor induction machine capable of operating in super synchronous as well as sub synchronous mode. The advantages of DFIG over the fixed speed induction generators are improved power quality, reduced mechanical stress and fluctuation and advanced energy capture [4].

The operations of DFIG connected to the grid are facilitated with the help of rotor side and grid side converter. It is the responsibility of the inverter connected to the rotor side to provide the necessary complementary frequency to maintain the stator frequency at a constant level, despite fluctuations in the mechanical power. The control of DFIG poses a twofold problem to compensate the speed fluctuations as well as reactive power. The stability and performance of the overall setup is to be maintained in the face of model uncertainties, external noise, variation of the internal machine parameters and speed. The problem of control becomes more involved in case of unbalanced grid connected operations. It is well known that unbalanced operations lead to the flow of negative sequence currents which in turn may lead to localized heating as well as pulsations in the electric torque. In critical applications, DFIGs must be disconnected from the grid when the voltage imbalance is more than $6 \%$ [5]. It was reported that even within this margin, torque pulsations can be reduced by injecting a compensation current in the DFIG rotor, but with their 
technique the torque pulsations could not be completely eliminated. The design of control strategy for the DFIG requires its simplified models which can be integrated with flexible AC transmission system (FACTs) based grid models. Such models can also be used for first hand analysis of the overall system. Ekanayake et al. in [6] presented a comparative study of the simplified models, wherein the authors have compared the fifth and third order model of DFIG followed by the study under faulted conditions. Z. Wang and Y. Sun in [7] presented the magnitude and frequency control of grid connected DFIG based on synchronized model for wind power generation. In this paper the numerical differentiation based incremental model around the nominal operating point of DFIG is used. The usefulness of such models can be verified from the results presented. It is worth to mention here that the typical ratings of wind turbines are between $800 \mathrm{~kW}$ to $3 \mathrm{MW}$, whereas wind farms range from $1 \mathrm{MW}$ to $200 \mathrm{MW}$ [8].

\section{AN OVERVIEW OF WIND TURBINES}

The wind turbine is a machine that converts kinetic energy from the wind into mechanical energy. If the mechanical energy is used to produce electrical energy, the device may be called a wind generator or wind changer. If the mechanical energy is used to drive machinery, for example to grinding grain or pumping water, the device is called a windmill or wind pump. Today's wind turbines are manufactured in a range of vertical and horizontal axis types. The nominal turbines are used for applications such as battery charging or auxiliary power on seafaring boats; whereas large grid connected arrays of turbines are becoming an increasingly large source of commercial electric power. The basic principle of wind turbine is as follows, the aerodynamic power is converted into mechanical power and then electrical power.

\section{A. Basic Perception of DFIG Based Wind Turbine:}

The mechanical power which is produced by the wind turbine is proportional to the cube of the wind speed i.e. $\mathrm{P}_{\mathrm{m}}$ $\propto v^{3}$. Where $P_{m}$ is the mechanical power of the wind and $v$ is the velocity of the wind speed. The maximum power which is obtained by the rotational speed of the wind turbine defers from different wind speeds. Hence the operation of variable speed is necessary to maximize the energy. The variable speed turbines are fed to the grid via a power factor control (PFC) which decouples the rotational speed of the wind turbine from the grid frequency, to enable variable speed operation. There are two basic concepts that exist for variable speed turbines. The first concepts are electric generator with a converter connected with in the stator windings and the grid network which is shown in Figure 1(a). For the rated power of the wind turbine the converter is to be designed. The generator is a synchronous machine which is mostly a permanent magnet. For the direct drive concepts a wind turbine with a DFIG has a converter connected to the rotor windings of the wound rotor induction machine, which is shown in Figure 1(b). This type of generator can be defined for a fraction $(\sim 30 \%)$ of the rated power. But the system ensures competent power conversion appropriate to variable rotor speed, which adjusts automatically in accordance with prevailing wind speeds [9]. The speed changing is possible by the directionally dependent transfer of slip power, which changes as follows. In the sub synchronous operating mode, the stator of the DFIG supplies power to the grid. In the super synchronous operating mode, both stator output power and the rotor slip power are fed into the grid. A variable speed wind turbine with full size converter and doubly fed induction generator is shown in Figure 1.

However, the converter has to be intended for the rated power of the turbine. This problem can be taken care of by using the DFIG, which has a converter connected to the rotor winding of the wound rotor induction machine (Figure 1(b)). Rated power has been reduced to $(25 \%-35 \%)$ in the case of DFIG. The main components of the wind turbine are given as follows.

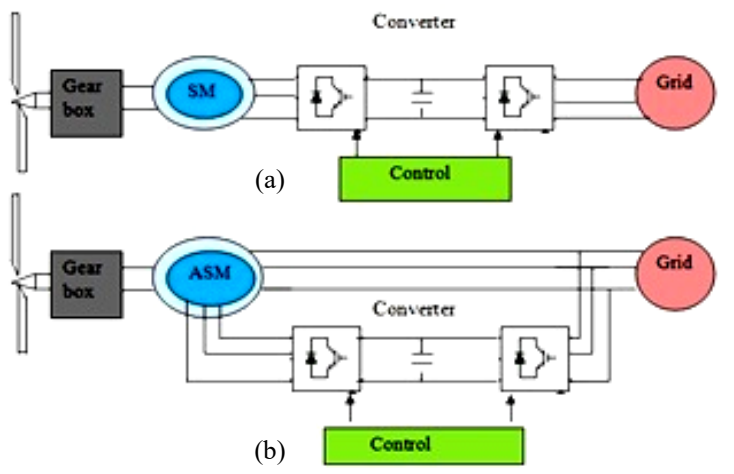

Fig. 1. Variable speed wind turbines (a) with full-size converter (b) with doubly-fed induction generator

1) Drive Train along with Aerodynamics:

The drive train has turbine, gear box, shafts and other mechanical components of wind turbine; a multi mass (in general two mass) model to be used for dynamic studies of wind turbines through DFIG [10]. A simplified aerodynamic model is sufficient, when the speed and pitch angle changes on the aerodynamic power during the grid faults. For stability investigation, the drive train system have to be approximated by the at least a two mass spring as well as damper model while the system response to heavy disturbance [11]. There is a flexible shaft during the turbine and generator masses are associated.

\section{2) Pitch Angle Control System:}

The "Pitch Control" is a technique so as to mechanically adjust the blade pitch angle to change the curve of the power coefficient of the turbine [12]. PI control is used to realize the pitch angle, in servo mechanism model with time control $\mathrm{T}_{\text {servo }}$ accounts for the practical response in the pitch angle control system. For the duration of the grid faults how quick the aerodynamic power can be reduced in order to stop more speeding is decided by the rate of change limit.

\section{B. Modeling of Wind Turbine:}

In this section wind turbine model is discussed for optimal operations of the wind turbine at different wind speeds [13]. It must be operated at its maximum power coefficient 
$\left(\mathrm{C}_{\text {Poptimum }}=0.3-0.5\right)$ i.e. at a constant tip speed ratio, intended for operation approximately its maximum power coefficient.

The aerodynamic power generated by wind turbine is given as follows.

$$
\begin{aligned}
& \mathrm{P}_{\text {aero }}=0.5 \rho \mathrm{A} C_{p}(\lambda, \beta) v^{3} \\
& \mathrm{C}_{\mathrm{p}}(\lambda, \beta)=\mathrm{c}_{1}\left(\frac{c_{2}}{\lambda_{i}}-c_{3} \cdot \beta-c_{4}\right) \cdot e^{-\frac{c_{5}}{\lambda_{i}}}+c_{6} \cdot \lambda
\end{aligned}
$$

$\frac{1}{\lambda_{i}}=\frac{1}{\lambda+0.08 \cdot \beta}-\frac{0.35}{\beta^{3}+1}$, and the coefficients

$\mathrm{c}_{1}=0.5176, \mathrm{c}_{2}=116, \mathrm{c}_{3}=0.4, \mathrm{c}_{4}=5, \mathrm{c}_{5}=21, \mathrm{c}_{6}=0.0068$

And $\lambda=\frac{\omega_{T} \cdot R}{v}$

$\mathrm{A}=$ Swept area of the blades $\left(=\pi \mathrm{R}^{2}\right)$,

$\lambda=$ Tip ratio speed,

$\omega_{T}=$ Rotational speed of the rotor, $\beta=$ Pitch angle,

$\mathrm{R}=$ Radius of the area covered through the blades.

The speed of a wind turbine determines the conversion efficiency from wind energy to mechanical energy, for a given wind velocity, blades geometry, and turbine

\section{AN OVERVIEW OF THE DFIG OPERATING PRINCIPLE}

The overview and operating principle of DFIG discussed in this section is also mentioned in [14]. The basic diagram of DFIG with converters is shown in Figure 2. The AC/DC/AC converter is divided into two components: The rotor side converter $\left(\mathrm{C}_{\text {rotor }}\right)$ as well as the grid side converter $\left(\mathrm{C}_{\text {grid }}\right) . \mathrm{C}_{\text {rotor }}$ and $\mathrm{C}_{\text {grid }}$ are voltage sourced converters with a common DC link via a capacitor. The grid converter uses a coupling inductor $\mathrm{L}$ to connect to the grid. The three phase rotor winding is connected to the $\mathrm{C}_{\text {rotor }}$ through slip rings as well as brushes, while the three phase stator winding is directly connected to the grid.

The power captured by the wind turbines is converted into electrical power by the induction generator and it is transmitted to the grid through both the stator as well as rotor windings. The control system generates the control signals to control the active, reactive power as well as currents, the injected frequency compensation to the rotor windings and lastly the DC voltage control of the common coupling link capacitor. Rotor side converter operates as an inverter and stator side converter operates as rectifier. When rotor moves below the synchronous speed in generating slip power is supplied to the rotor.

The mechanical power as well as the stator electric power output is given as below

$$
\begin{aligned}
& P_{r}=T_{m} * \omega_{r} \\
& P_{s}=T_{e m} * \omega_{s}
\end{aligned}
$$

The mechanical dynamical equations for the lossless generator are described below.

$$
J \frac{d \omega_{r}}{d t}=\left(T_{m}-T_{e m}\right)
$$

At steady state, the mechanical torque balances the electromagnetic torque substitute on the machine and hence the relations are as follows.

$$
\begin{gathered}
T_{m}=T_{e m} \text { and } P_{m}=\left(P_{s}+P_{r}\right) \quad \text { it follows that: } \\
P_{r}=\left(P_{m}-P_{s}\right)=T_{m} \omega_{r}-T_{e m} \omega_{s}=-s P_{S}
\end{gathered}
$$

where $s=\left(\omega_{s}-\omega_{r}\right) / \omega_{s}$ is defined as the slip of the generator in per unit and $\mathrm{J}$ is inertia constant.

\section{VOLTAGE SOURCE CONVERTER CONTROLLER}

A voltage source converter (VSC) is used in DFIG to control the rotor and grid side converter as well as DC link voltage also. The general schematic diagram of a DFIG and Wind Turbine along with VSC Converters with a common DC link is shown in Figure 3. The advantage of VSC based converter is that it uses very small power converter on the rotor side. The rotor side converter supplies the compensated current for frequency compensation. Wide variation in the wind speed is taken care of by gear train with adjustable gear ratio. VSC control circuitry provides the necessary control signals for both rotor side as well as grid side converters. Further, the control strategy maintains a constant DC voltage of the common DC link.

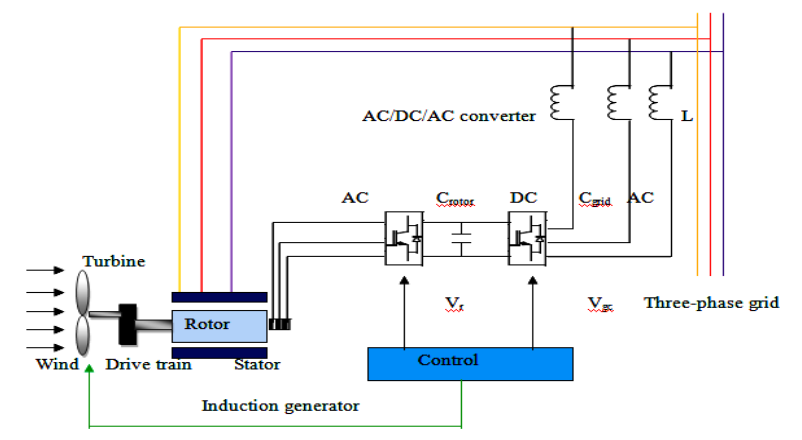

Fig. 2. Basic diagram of Doubly Fed Induction generator with converters

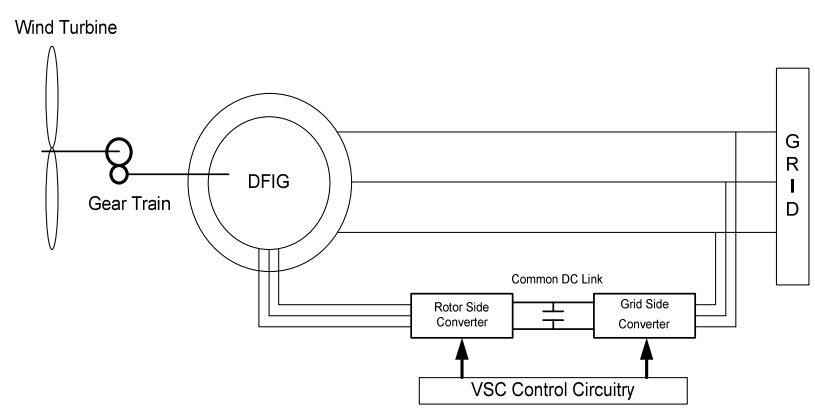

Fig. 3. The general schematic diagram of DFIG control

The transfer function of the overall system is obtained either via elementary modeling or using the numerical differentiation, on the basis of which the controller for the VSC is designed. Component modules of the VSC based common 
DC link controller is shown in Figure 4. $P_{g}^{\text {set }}$ and $Q_{g}^{\text {set }}$ shown in the diagram are the set-point values of the real and reactive power across the terminals of the wind turbine. The power factor can be made unity by letting $Q_{g}^{\text {set }}$ to zero. In this case all reactive power to the DFIG is provided via the rotor-side converter. Further, the reactive power set point value can be adjusted to maintain the voltage constant at the turbine terminals [8].

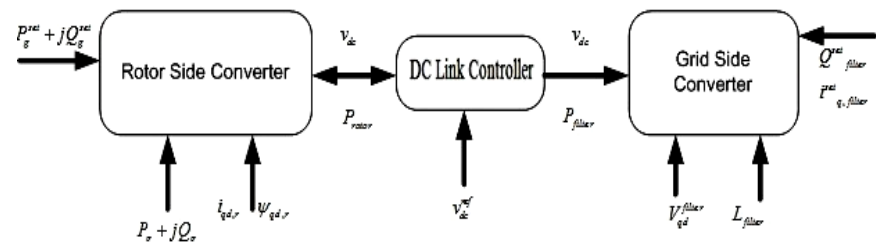

Fig. 4. Component modules of the VSC based common DC link controller

\section{A. Simplified System Model:}

The system chosen for the study of the supervisory control is a wind turbine connected to a step-up transformer and a local load at $1 \mathrm{~km}$. The point of common coupling at the load side is connected to the utility grid via a $30 \mathrm{~km}$ long transmission line [15]. The grid connected wind turbine system is shown in Figure 5. The supervisory control used in this paper decides the reactive power requirements from the perturbations in the power point coupling (PCC) voltage and the wind speeds. In general, for wind farms or even few wind turbines connected to local load and utility grid, it is difficult to obtain the analytical model of the overall system.

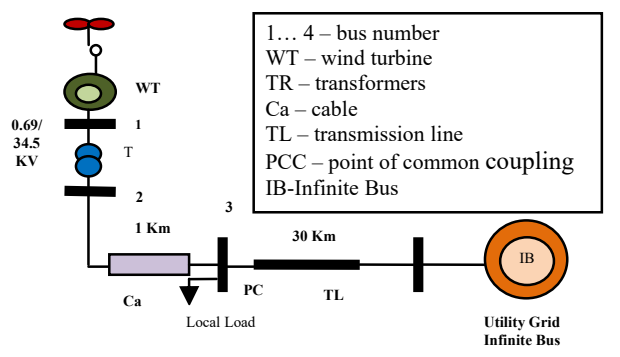

Fig. 5. Grid connected wind turbine system

\section{B. Design of Supervisory Controller:}

The PID controller for the sample system was designed considering the $10 \%$ overshoot and more than 60 degrees of phase margin. The gains of the PID supervisory controller parameters are given in Table I [8].

TABLE I: GAINS OF THE PID SUPERVISORY CONTROLLER

\begin{tabular}{|c|c|c|c|}
\hline Parameters & $k_{i}$ & $k_{p}$ & $k_{d}$ \\
\hline Gains & 6.7122 & 0.4635 & 0.0009 \\
\hline
\end{tabular}

This paper presents an experimental study of the DFIG with help of seven PI controllers for the internal loops of the DFIG and one PID controller for the supervisory control of the system under study as proposed in [15]. This model is utilized to design the SOF controller for the proposed system and results are compared with the results in Table I.

\section{StATIC OUTPUT FEEDBACK TECHNIQUE}

Various techniques are available to design a PI controller. Among these techniques static output feedback (SOF) is the one that can be applied to the controller to make the system globally stable. Figure 6 shows that the input to the PI controller is the error between the set point value and the measured value. Controllers output can be written as follows.

$$
u=k_{P} y_{0}+k_{I} \int y_{0} d t
$$

where, $k_{P}$ and $k_{I}$ are controller constants. Equation (6) can be rewritten as follows.

$$
u=\left[\begin{array}{ll}
k_{P} & k_{I}
\end{array}\right]\left[y_{0} \int y_{0}\right]^{\mathrm{T}}
$$

Therefore, measured output will be:

$$
y=\left[y_{0} \int y_{0}\right]^{\mathrm{T}}
$$

and PI controller can be described as follows:

$$
\mathrm{G}_{\mathrm{C}}=\left[k_{P} k_{I}\right]
$$

The PI controller is in closed loop system as shown in Figure 6.

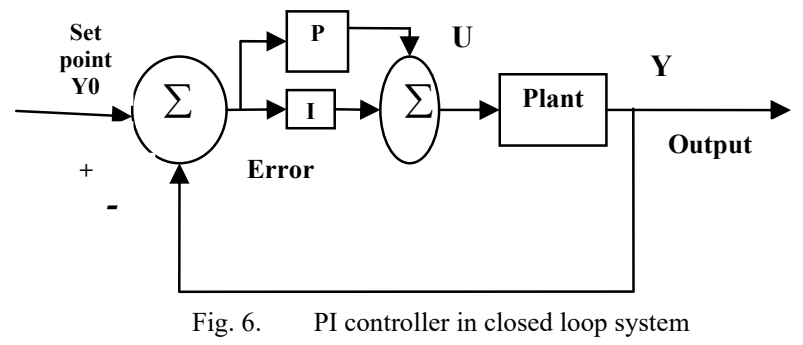

PI controller design based on SOF method uses a pair of coupled linear matrix inequalities. SOF controller that guarantees the closed loop system is impulse free and stochastically stable for the tuning of PI controller [16].by using LMI Toolbox of Matlab we get the Gain of the SOF, PI Controller as given in Table II.

TABLE II: GAINS OF THE SOF PI CONTROLLER

\begin{tabular}{|c|c|c|}
\hline Parameters & $k_{p}$ & $k_{i}$ \\
\hline Gains & 0.0814 & 4.6647 \\
\hline
\end{tabular}

\section{Simulation And Results}

\section{A. Simulation and Response of the DFIG System:}

Figure 7 represents the detailed doubly fed induction generator Matlab diagram and voltage $(\mathrm{Pu})$ at DFIG terminals presented in Figure 8. Furthermore Figure 9 shows the active power delivered. The reactive power requirement of the DFIG is presented in Figure 10. DC link voltage $(\mathrm{Pu})$ at the common link capacitor of DFIG is presented in Figure 11. 


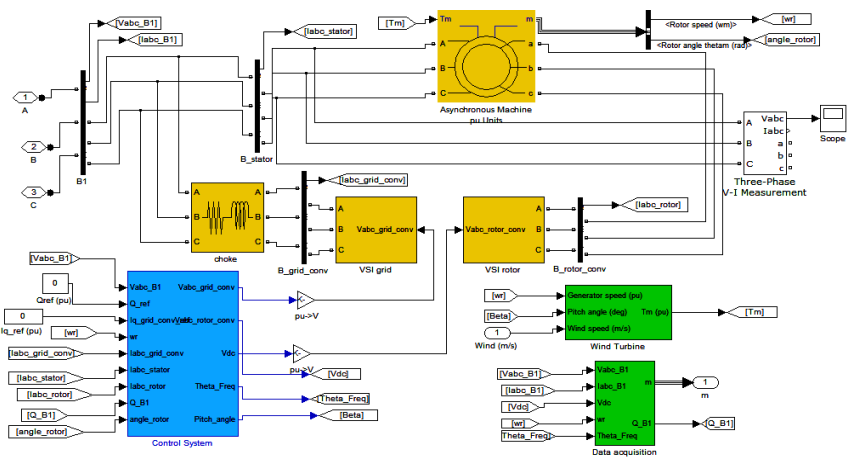

Fig. 7. Detailed DFIG wind turbine diagram

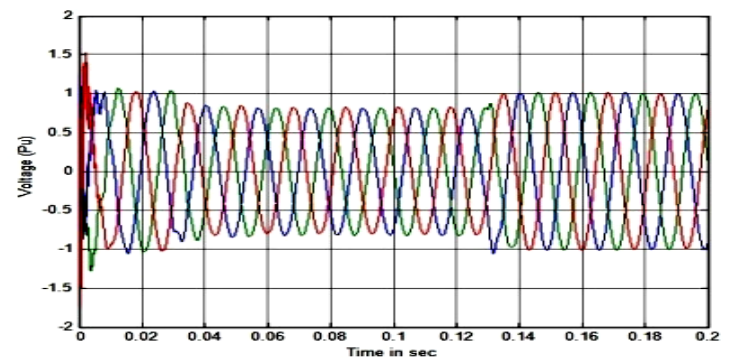

Fig. 8. Voltages at the DFIG terminals

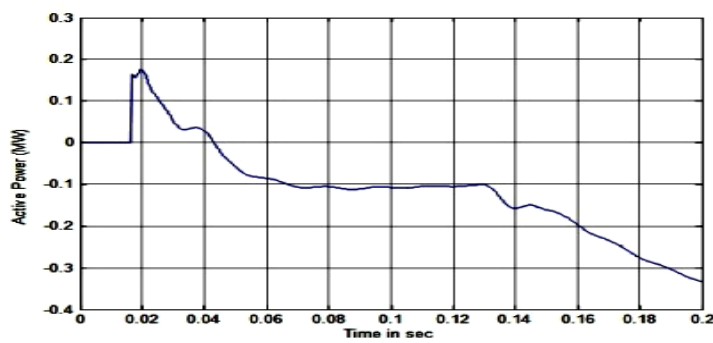

Fig. 9. Active power delivered

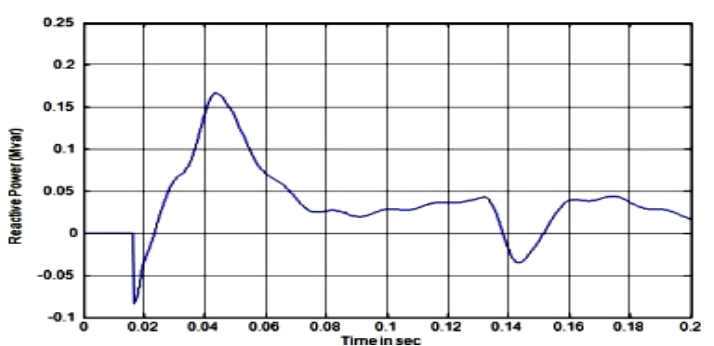

Fig. 10. Reactive power requirement of the DFIG

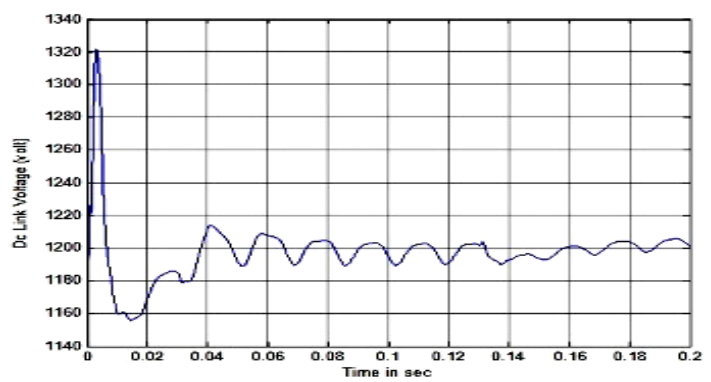

Fig. 11. DC link voltage at the common link capacitor

\section{B. Response of Supervisory Control with PID Controller:}

The response of the supervisory PID designed in [8] on the system under study is as shown in Figure 12. Clearly the open loop system despite being stable has steady state error of $100 \%$. Further, there is an under shoot in the response of the open loop system due to the non-minimum phase nature of the system. Step response of the supervisory reactive power controller (Conventional PID-controller) in [8] is shown in Figure 12.

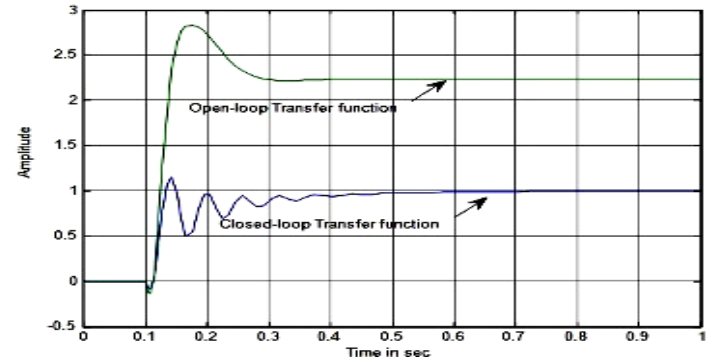

Fig. 12. Step response of the supervisory reactive power controller (Conventional PID controller)

\section{Response of Supervisory Control with PI Controller by means of SOF Method}

Using PI controller parameters designed in Table II. The step response of the system under study for the supervisory reactive power control was studied. The step response of the system is as shown in Figure 13. It is clear from the comparison of the results of the PID control in [8] and the ones reported in this work, that our controller has resulted in suitably damped supervisory control without compromising the speed of response of control loop. Step response of open as well as close loop reduced order system by PI controller using SOF method is shown in Figure 13. Comparison between the step responses of Figures 12 and 13 is presented in Table III.

TABLE III: COMPARISON OF SETTLING TIME AND OVERSHOOT BETWEEN SUPERVISORY PID CONTROLLER AND PI CONTROLLER USING SOF METHOD

\begin{tabular}{|c|c|c|}
\hline Figure & $\mathbf{1 2}$ & $\mathbf{1 3}$ \\
\hline Controller & supervisory PID & SOF based PI \\
\hline Rise Time & 0.0152 & 0.2133 \\
\hline Settling Time & 0.5291 & 0.5276 \\
\hline Settling Min. & 0.4933 & 0.9111 \\
\hline Settling Max. & 1.1512 & 0.9926 \\
\hline Over shoot & 15.1985 & 0 \\
\hline Under shoot & 8.1860 & 1.5474 \\
\hline Peak & 1.1512 & 0.9996 \\
\hline Peak Time & 0.1419 & 1 \\
\hline
\end{tabular}

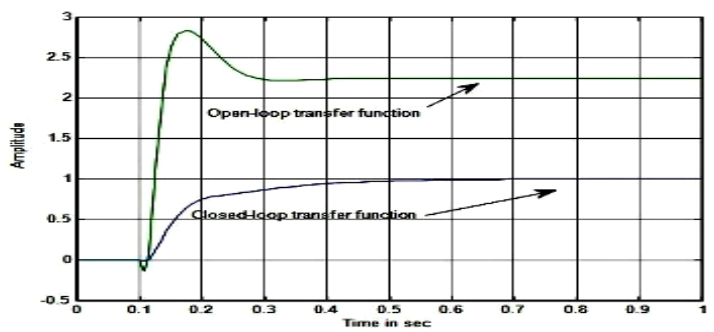

Fig. 13. Step response of open loop and close loop reduced order system with PI controller using SOF method 


\section{Comparison between supervisory PID and PI-controller using SOF method:}

A comparison of settling time and overshoot is given in Table III. The comparison of the performance parameters for controllers as given in Table III, are concluded as: (i) The designed PI controller is able to reduce the steady state error to zero as the existing one, (ii) The peak overshoot has been reduced to zero, the response is no more under damped and (iii) The response speed is almost the same as that of the existing controller or it is slightly better. Thus the designed controller in this paper helps to eliminate the reactive power fluctuations in the DFIG system.

\section{CONCLUSION}

Although the supervisory PID controller improves the system response in comparison to the open loop system yet oscillations are not entirely removed. PI controller using the SOF method not only improves the system response but in addition decreases the percentages overshoot to zero. PI controller using SOF technique demonstrates that the system settles down in smaller time as in the case when supervisory PID controller employed. Results presented in this paper shows that the settling time is reduced three percent approximately and that the percentage overshoot reduces to zero with PI controller using SOF method in comparison to the supervisory PID controller. Hence, it is accomplished that the SOF control technique provides another alternative for the design of controllers in DFIG.

\section{ACKNOWLEDGMENT}

The authors acknowledge the partial financial support from the Indian Institute of Technology (Banaras Hindu University), Varanasi (U.P.) India for carrying out this work. This work is heartily devoted to sweet memories of the first author's great Grand Mother Patiraji Devi who has passed away on November 24, 2014.

\section{Appendix: Simulation Data}

DFIG (Pu): $R_{s}=0.00920, \quad R_{r}=0.00760, \quad L_{s}=0.190$, $L_{r}=0.07920, \quad L_{m}=4.59260$

Controller gains (Pu):

Rotor-side converter:

$\mathrm{PI}_{1}$ and $\mathrm{PI}_{3}$ Controllers: $k_{\mathrm{p}}=0.0252, k_{\mathrm{i}}=10.4832$

$\mathrm{PI}_{2}$ and $\mathrm{PI}_{4}$ Controllers: $k_{\mathrm{p}}=0.9995, k_{\mathrm{i}}=20$

Grid-side converter:

$\mathrm{PI}_{5}$ and $\mathrm{PI}_{6}$ Controllers: $k_{p}=0.7147, \mathrm{ki}=7.1515$

DC link module: $v_{d c}^{r e f}=1, \quad C_{d c}=12.7227, k_{p}=0.9544$, $k_{i}=3.8175$

Transfer function of the 6th-order reduced model:

\section{REFERENCES:}

[1] F. Yao, R. C. Bansal, Z. Y. Dong, R. K. Saket, J. S. Shakya, "Wind energy resources: theory, design and applications",in Handbook of Renewable Energy Technology, Section I: Wind Energy and Their Applications, pp: 03-20, World Scientific Publishing House, Singapore, 2011

[2] A. M. Atallah, A. Y. Abdelaziz, M. Ali, R. K. Saket, O. P. Bharti, "Reliability assessment and economic evaluation of offshore wind farm using stochastic probability", International Conference on Power, Circuit and Information Technologies, Bangalore, India, 27th - 28th April, 2015

[3] R. C. Bansal, A. F. Zobaa, R. K. Saket, "Some issues related to power generation using wind energy conversion system: an overview", International Journal of Emerging Electric Power System, Vol. 3,No. 2, pp: 1-19, 2005

[4] H. Sun, Y. Ren, H. Li, Z. An, J. Liu, H. Hu, H. Liu, "DFIG wind power generation based on back-to-back PWM converter," 2009 IEEE International Conference on Mechatronics and Automation, pp. 22762280, Changchun, China, August 9-12, 2009.

[5] T. Brekken, N. Mohan, "Control of a doubly fed induction wind generator under unbalanced grid voltage conditions", IEEE Trans. Energy Conv., Vol. 22, No. 1, pp. 129-135, 2007

[6] J. B. Ekanayake L. Holdsworth, N. Jenkins, "Comparison of 5th order and 3rd order machine models for doubly fed induction generator (DFIG) wind turbines", Electric Power Systems Research, Vol. 67, pp. 207-215, 2003

[7] Z. Wang, Y. Sun, G. Li, B.T.Ooi, "Magnitude and frequency control of grid connected doubly fed induction generator based on synchronized model for wind power generation", IET Renew. Power Generation, Vol. 4, No. 3, pp. 232-241, 2010

[8] H. S. Ko, Supervisory voltage control scheme for grid-connected wind farms, Ph.D. Dissertation, Dept. Elect. and Comp. Eng., Univ. of British Columbia, Vancouver, BC, Canada, 2006

[9] S. Engelhardt, I. Erlich, C. Feltes, J. Kretschmann, F. Shewarega "Reactive Power Capability of Wind Turbines Based on Doubly Fed Induction Generators" IEEE Trans. Energy Conv., Vol. 26, No. 1, pp. 364-372, 2011

[10] M. Rahimi, "Dynamic performance assessment of DFIG-based wind turbines: a review," Renew. Sustain. Energy Rev., Vol. 37, pp. 852-866, 2014

[11] X. Xi, H. Geng, G. Yang, "Enhanced model of the doubly fed induction generator-based wind farm for small-signal stability studies of weak power system," IET Renew. Power Gener, Vol. 8, No. 7, pp. 765-774, 2014.

[12] B. Bossou, M. Karim, A. Lagrioui, M. Taoussi, "Observer back stepping control of DFIG-Generators for wind turbines variable-speed FPGAbased implementation,” Renewable Energy, Vol. 81, pp. 903-917, 2015

[13] A. Tapia, G. Tapia, J. X. Ostolaza, J. R. Saens, "Modeling and control of a wind turbine driven doubly fed induction generator", IEEE Transactions on Energy Conversion, Vol. 18, No.2, pp. 194-204, 2003

[14] B. Dosijanoski, "Simulation of Doubly Fed Induction Generator in a Wind Turbine", XI International PhD Workshop OWD, Wisła, Poland, October 17-20, 2009

[15] H. S. Ko, G. G. Yoon, N. H. Kyung, W. P. Hong, "Modeling and control of DFIG-based variable speed wind-turbine", Electric Power System Research, Vol. 78, pp. 1841-1849, 2008

[16] E. K. Boukas, Control of Singular Systems with Random Abrupt Changes, Springer, 2008

\footnotetext{
$0.000324 \mathrm{~s} 6-1.75 \mathrm{~s} 5-2366 \mathrm{~s} 4+7.9 \mathrm{e} 6 \mathrm{~s} 3+7.5 \mathrm{e} 9 \mathrm{~s} 2+5 \mathrm{e} 12 \mathrm{~s}+2.18 \mathrm{e} 14$

$\mathrm{G}(\mathrm{s})=\frac{\mathrm{s} 6+2340 \mathrm{~s} 5+8.67 \mathrm{e} 6 \mathrm{~s} 4+4.79 \mathrm{e} 9 \mathrm{~s} 3+2.7 \mathrm{e} 12 \mathrm{~s} 2+1.27 \mathrm{e} 14 \mathrm{~s}+9.6 \mathrm{e} 14}{4}$
} 